\title{
INCIDENCE OF DEATH FROM TUMOURS OF THE URINARY BLADDER
}

\author{
BY \\ R. A. M. CASE \\ Chester Beatty Research Institute, Institute of Cancer Research, University of London
}

The investigation of possible environmental risks that may lead to an increase in the frequency of the occurrence of tumours of the urinary bladder requires a measure of the frequency with which the condition will be expected to occur in a sample of the population not regarded as being subjected to any known environmental hazard. For practical purposes, since no such population can be enumerated and defined, it is proposed to regard the total male population of England and Wales as representing such a sample.

If the frequency of the disease shows any marked tendency to age specificity, and if other influences at present not elucidated which vary at different dates produce a marked effect, then this measure must take into account both the age composition of the population under consideration, and the varying effect of contemporaneous conditions.

At present, English morbidity statistics have not reached a sufficiently high degree of excellence to allow a reliable estimate of this kind to be formed from them. However, the mortality statistics are of sufficient quality, and especially so in the case of bladder tumours, where all certificates showing mention of bladder tumour, classified into "cancer" or "tumours, benign and unspecified", have been collected separately at the General Register Office since 1921. This separation applies to males only, but since the immediate programme of investigation of risk is confined to predominantly male occupations, this limitation is at present immaterial. Moreover, this separation into certificates mentioning tumour of the bladder overcomes the technical difficulties introduced by the change of death certificate classification introduced in 1940 (Registrar General, 1949), if we adopt the convention of speaking of "death certification rate" instead of "death rate".

In fact, this "certification rate" will differ but slightly from the "death rate", since 97.5 per cent. of the death certificates are in fact assigned by the
General Register Office to bladder tumour as the cause of death.

The other requirement for the estimation of an environmental risk is a detailed knowledge of the population at risk, both in regard to the dynamics of repletion, and the number of cases of the disorder discovered. In the present instance of bladder tumour, the hazards to be investigated are in the first case industrial, and many large industries do in fact possess records of dates of employment of men, possibly with the age at the time of employment. The type of estimation discussed here relies on the availability of this information, and is therefore largely applicable to possible hazards where the co-operation of the industry can be secured, or to the internal investigation of sections of the industry by the concerns themselves.

Theoretically, an estimate of the expected number of death certificates taking into account the factors enumerated could be made from an exhaustive analysis of the age-specific death certification rates for the appropriate years, and from the actual depletion by other causes of death of the population under consideration.

In practice, it is unlikely either that the complete death records of past works' populations can be obtained, or that the interested persons, frequently factory medical officers, will have access to the required demographical data or an inclination to obtain an estimate by such laborious means.

It is possible to make an approximation to the required estimate by using mean mortality data (life tables) for England and Wales, and by assuming certain relationships, discussed below, to be essentially of a linear nature throughout the three decades under consideration.

Another consequence of the separation of bladder tumour death certificates from other death certificates is that it has been possible to form an alphabetical index of such certificates for males in England and Wales. This index now covers the years 
1936-50 and will be kept up-to-date. Should need arise the index can be extended to cover the period 1921-35 also. This index makes it possible for the Chester Beatty Research Institute to afford some help to works' medical officers or other interested persons in checking populations described by name and date of birth to find prima facie evidence of the possible number of bladder tumour death certificates that have actually occurred. In many cases further investigation will, of course, be necessary to obtain evidence of identity.

This observed frequency of death certificates can obviously only be expressed in whole numbers, and the relationship of these observed numbers to the expected frequency can be assumed to take the form of a Poisson distribution. Thus, for the observed number of death certificates, a limiting frequency for any given level of significance can be determined, and can be compared with the estimated frequency determined as described below.

The purpose of this communication is to give the mathematical and demographical background to the method discussed. For practical use in factories, tables have been constructed from the equations, and these tables, with instructions for their use, will form the subject of a separate communication (Case, 1953).

Given the numbers of the population involved, the date of starting work in the environment to be considered, and the age of the individual at starting, the equations allow of a complete solution, with fiducial limits, of the expected frequency without further recourse to demographical data. Withdrawals from the environment due to change of occupation or retirement do not affect the estimate required.

\section{Methods AND MATERIALS}

We had at our disposal the death certificates mentioning "cancer of the bladder" and "tumours of the bladder benign and unspecified" for the years 1921-50, for males, in England and Wales. Before all these data had become available, the certificates for 9 years, scattered throughout the 30-year period, had been used for a preliminary computation. This sample, when allowances for temporal differences had been made, differed so little from the total pooled data that the calculations based on it are used in much of the ensuing discussion. These data will be referred to as the "basal data" and indices calculated from them denoted by the suffix $(b)$.

The certificates for each year were examined and allocated to age groups, using the class intervals 0 -, 15-, 25-, 35-, 40-, and thence by 5-year groups to a final group of 85 and over. Each annual age group was amalgamated into a quinquennial group. The age specific certification rates for each quinquennium were calculated from these data, and from the Registrar
General's "Estimate of Population, Total Males, England and Wales," for the appropriate quinquennia (Registrar General, 1921-50). The equivalent of the Comparative Mortality Index (C.M.I.; Registrar General, 1949), to which we shall refer as the Comparative Certification Index (C.C.I.), was computed from these data with the quinquennium 1936-40 (mid-point 1938) as the base. The crude certification rates were also calculated for these quinquennia. The values are shown in the Table.

TABLE

CRUDE AND CORRECTED ANNUAL CERTIFICATION RATES PER $10^{\circ}$ MALES LIVING AT ALL AGES, AND COMPARATIVE CERTIFICATION RATE (C.C.I.) WITH QUINQUENNIUM 1936-1940 AS BASE

\begin{tabular}{|c|c|c|c|c|c|c|}
\hline Date & $\begin{array}{c}1921 \\
\text { to } \\
1925\end{array}$ & $\begin{array}{c}1926 \\
\text { to } \\
1930\end{array}$ & $\begin{array}{c}1931 \\
\text { to } \\
1935\end{array}$ & $\begin{array}{c}1936 \\
\text { to } \\
1940\end{array}$ & $\begin{array}{c}1941 \\
\text { to } \\
1945\end{array}$ & $\begin{array}{c}1946 \\
\text { to } \\
1950\end{array}$ \\
\hline Crude Rate .. & $42 \cdot 5$ & $48 \cdot 9$ & $55 \cdot 0$ & $59 \cdot 4$ & $72 \cdot 2$ & $83 \cdot 3$ \\
\hline C.C.I. . . & $\overline{0.9224}$ & $\overline{0.9792}$ & $\overline{1.0067}$ & $\overline{1.0000}$ & $\overline{1 \cdot 1288}$ & $\overline{1 \cdot 2335}$ \\
\hline Corrected Rate & 54.9 & $58 \cdot 2$ & $58 \cdot 8$ & $59 \cdot 4$ & $67 \cdot 1$ & $73 \cdot 3$ \\
\hline
\end{tabular}

The corrected certification rates for the same quinquennia were calculated by multiplying the crude certification rate for the quinquennium $1936-40$ by the C.C.I. for the other quinquennia. The age specific certification rates for the pooled data of the 30 years 1921-50 were calculated. These are shown for reference in Fig. 1, but the actual data used are the comparable age specific rates for the basal data.

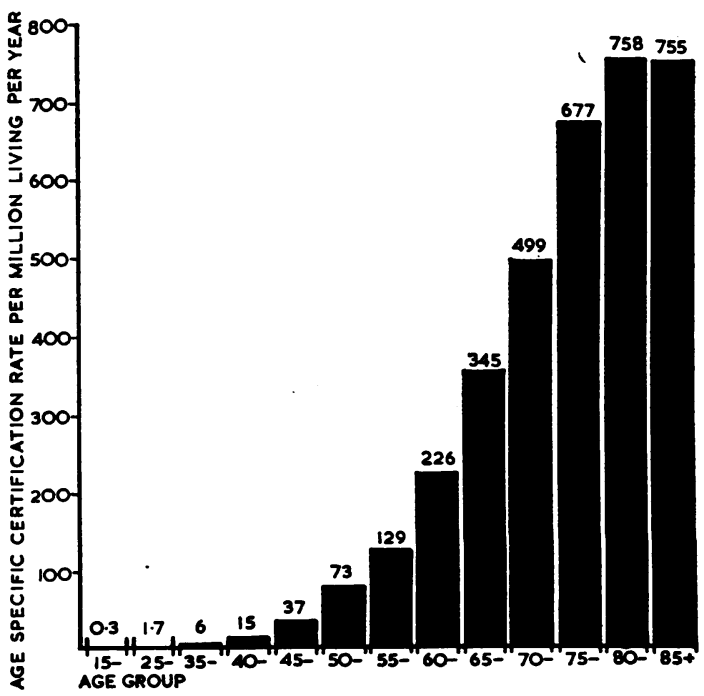

FIG. 1.-All tumours of the bladder. Mean annual age specific certification rate for males in England and $W$ ales, from the pooled data, 1921-50. 
The effect of all mortality has been summarized in the British Life Tables and Estimated Life Tables; and the tables for the census years 1921 and 1931, and the estimated table for 1948 were selected as the most appropriate for the present purpose (Registrar General, $1948 ; 1951)$. From these life tables and from the bladder tumour data discussed above it was possible to construct tables that would show the expected incidence of death certification in a cohort of given age attenuated by the mean mortality values for England and Wales. This attenuation has, of course, changed with the passing of time.

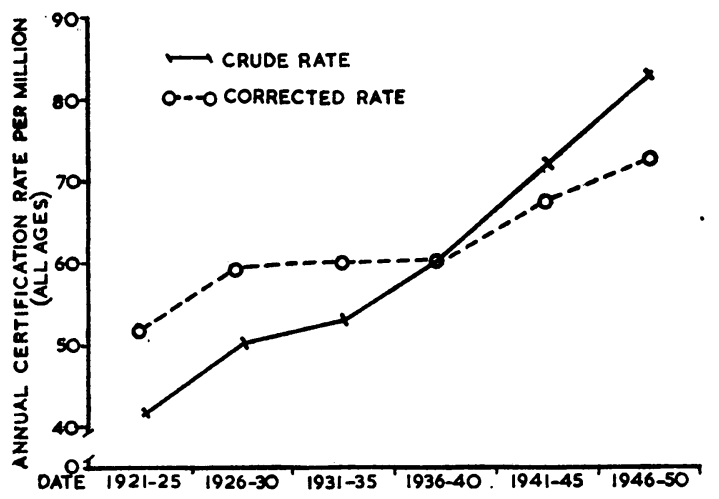

Fig. 2.-All tumours of the bladder. Crude and corrected mean annual certification rates for males in England and Wales, 1921-50.

\section{RESULTS}

(1) The crude certification rates and the corrected certification rates are shown in Fig. 2. The two rates are expressed per million males living at all ages per year, and it is apparent that there has been

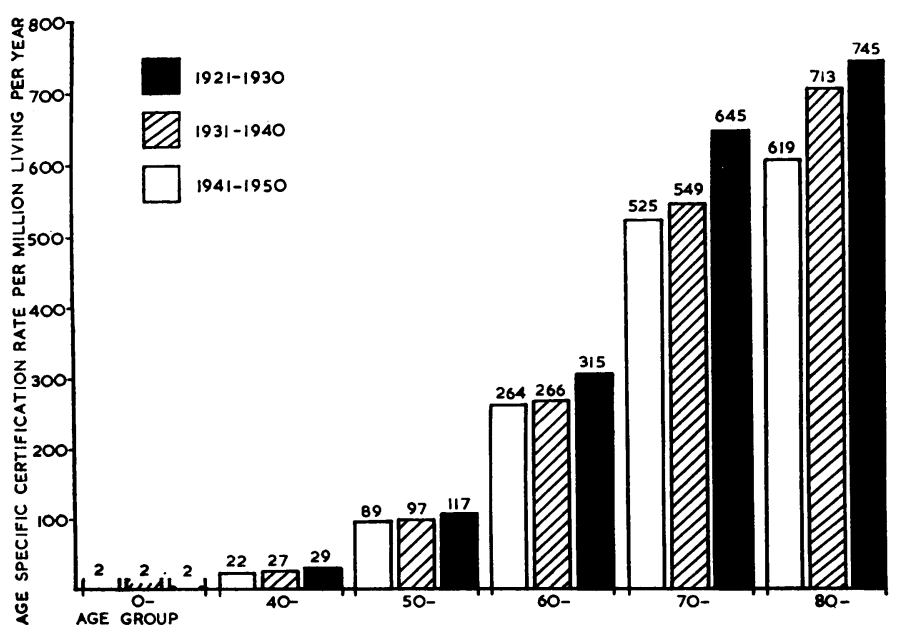

FIG. 3.-All tumours of the bladder. Age specific certification rate for males in England and Wales, for the three decennia, 1921-30, 1931-40, and 1941-50. a large increase in the crude certification rate in the last 30 years. When the effects of the changing age structure of the population are removed, a considerable residuum of increase remains. Since there has been little or no improvement in methods of diagnosis of the terminal stages of bladder tumour since the use of the cystoscope became widespread in the early twentieth century, it is suggested that this residual increase is a real increase in the frequency of the condition.

(2) The histogram of the age specific certification rates for the pooled data of the period 1921-50 has already been shown in Fig. 1.

Histograms, with a rather coarser age grouping, for the three decades 1921-30, 1931-40, and 1941-50, are shown in Fig. 3. The pattern is essentially the same in each case, and the real increase of certification discussed above is due to increments of approximately similar proportions in each age group. Furthermore, Fig. 3 shows that no great error is introduced by the assumption of a linear change with respect to time in each age group.

The histogram of the age specific certification rates for the basal data (Fig. 4, opposite) may be regarded as forming a representative pattern for the whole period. The diagram shows the high degree of age specificity, with a fall in rate after the age of 85 . This fall, though not relevant to the substance of this paper, is of interest because it suggests that for any intensity of causative stimulus (the sum total of all factors producing, in this case, bladder tumour) there is an immune and a non-immune (in a statistical sense) class of the population. An alteration in the intensity of the causative stimulus might be expected to vary the proportions of these two classes.

(3) The effect of the increasing certification rate and the decrease in mortality from all causes in younger age groups with the passage of time, coupled with the age specificity, will interact to influence the incidence of death certification from bladder tumour in a population considered at different dates. 


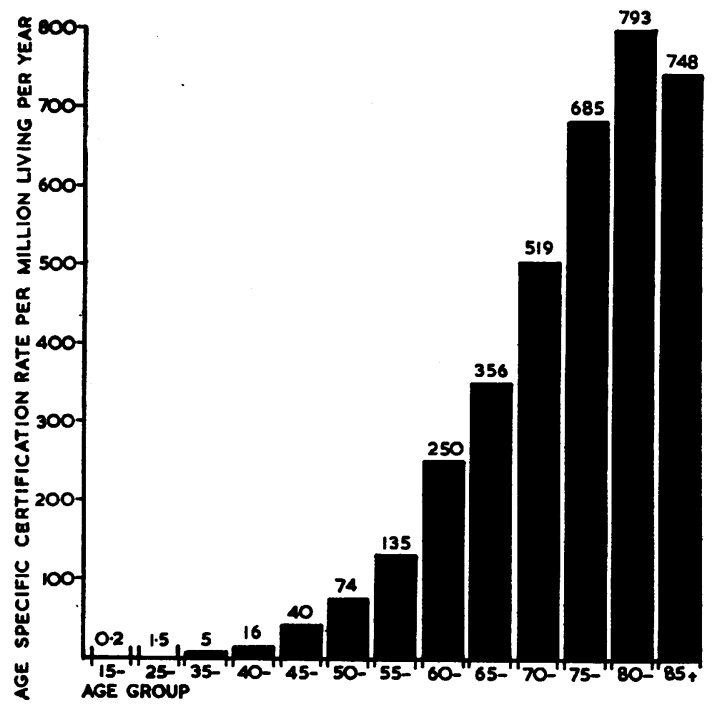

FIG. 4.-All tumours of the bladder. Mean annual age specific certification rate for males in England and Wales, from the basal data for nine years scattered between 1921 and 1950.

Fig. 5 shows this effect for cohorts of initial age 30 considered as being attenuated by all mortality at the risks current in 1921, 1931, and 1948, and acquiring bladder tumour death certificates at the risks prevalent in these years. The whole figure is computed from the death certificates for

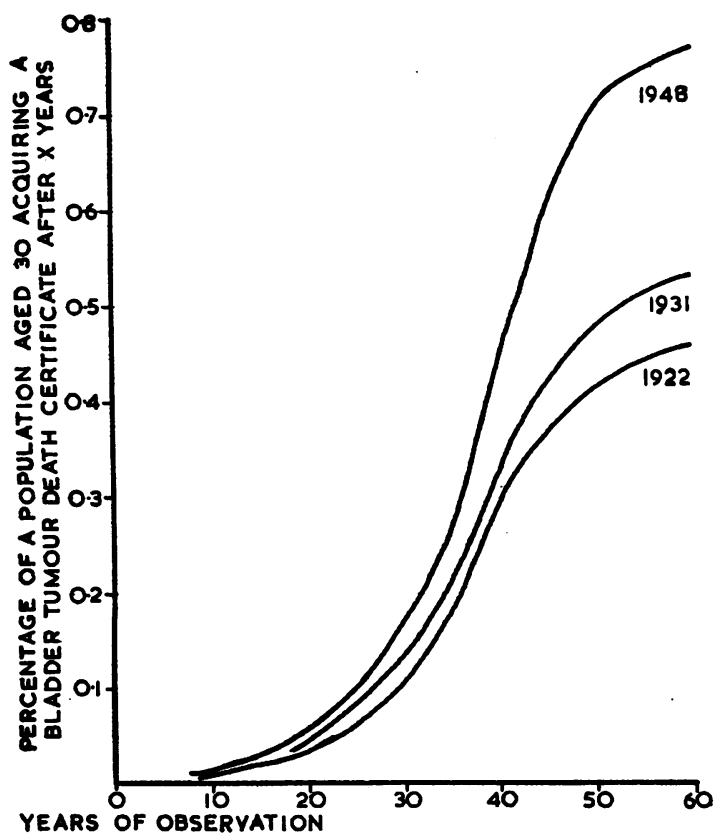

FIG. 5. - Combined effect of changes in certification rate and of all mortality (Males in England and Wales). the 3-year groups 1921-23, 1930-32, and 1947-49, loaded with the life table mortality from the years 1921, 1931, and 1948 respectively. The 1921 table is used because it is based on a census year.

The figures for the incidences attained at any stated age are reasonably linear if plotted against date, and have been assumed to be so between the limiting cases, and also for cohorts of initial ages between 20 and 50 years of age.

\section{DisCUSSION}

The results reported above show that the incidence of death certification mentioning bladder tumour is highly age specific, and is affected to a considerable degree by contemporaneous conditions.

They also show that there is a marked real increase in the annual corrected certification rate over the last 30 years, an increase which is very unlikely to be due in any large measure to improvement in diagnosis.

The results obtained now allow us to write a series of equations which will give a reasonable estimate of the expected incidence for men entering observation between the ages of 20 and 50, and between the years 1921 and 1950 .

\section{Derivation of the Estimating Equations}

Required.-An estimate, $R$, of the incidence of bladder tumour being mentioned on a death certificate, such that $R$ gives the expected value for males at the current mean rate for England and Wales for the date of observation. For convenience, $R$ is to be estimated as the percentage incidence in a theoretical cohort of men, whose age at the time of first observation is $Z$, and who are observed for $x$ years. The date of the mid-point of the period of observation is $w$.

\section{Known.-}

(1) The age specific certification rates $[M(a . w)]$ at each of $\boldsymbol{n}$ age groups $q$ whose mid-points are $a$ years of age and consisting of $C$ years. $\quad M(a . w)$ is expressed as the rate per million living per year. If the age at the mid-point of the first age group $q_{1}$ considered is $Z$, then $a$ can take the values $Z$,

$$
\begin{aligned}
\left(Z+\frac{C_{1}+C_{2}}{2}\right),\left(Z+\frac{C_{1}+C_{2}}{2}+\frac{C_{2}+C_{3}}{2}\right), \ldots \\
\left(Z+\frac{C_{1}+C_{2}}{2}+\frac{C_{2}+C_{3}}{2} \ldots+\frac{C_{(n-1)}+C_{n}}{2}\right)
\end{aligned}
$$

where, as is the case here, $C$ is not necessarily constant, $C_{1}$ is the value in the group $q_{1}$ whose mid-point is $Z$, and the last value, $C_{n}$, is not finite. The last age group $q_{n}$ is that class of the population aged over 85 years.

(2) The fraction $\left(1_{Z}\right)$ of an original population observed from birth to the age $Z$ (Registrar General, 1948, 1951) for the years 1921, 1931, and1948. From this the fraction of a population aged $Z$ at first observation surviving to 
each of the age groups with mid-point $a$ can be computed from the expression:

$$
\left(\frac{1}{1_{Z}}\right)_{w}
$$

where $w=$ the date of the relevant life table and here can only be 1921, 1931, or 1948 .

(3) From the above it has been possible to determine the ultimate frequency of certification in cohorts attenuated by mortality at the rates current in 1921, 1931, and 1948, and acquiring their bladder tumour death certificate at the rates current in these years.

Then.-An estimate $i(Z . w . q)$ can be made of the percentage incidence of certification at any age group $q_{p}$ from the formula:

$$
i(Z . w . q)=\sum_{\dot{q}_{1}}^{q_{p}} \frac{C(M . a . w)}{10,000}\left(\frac{1_{a}}{1_{Z}}\right)_{w}
$$

which will reach a limiting value, the terminal incidence, $I(Z . w)$ when $q=q_{n}$, which in this particular case is 85 and over. Thus:

$$
I(Z . w)=\sum_{q_{1}}^{q_{n}} \frac{C(M . a . w)}{10,000}\left(\frac{1_{a}}{1_{Z}}\right)_{w}
$$

This value $I(Z . w)$ cannot be exceeded because $1_{a}$ becomes zero after $q=85+$. However, since the age group $q=85+$ has an indeterminate mid-point, the value $I(Z)$ cannot be regarded as a special case of $i(Z)$, but only as its upper limit.

By a possibly fortuitous combination of circumstances, the values of $i(Z . b . q)$ determined from the basal data for the values of $Z=20,30,40$, and 50 , and $X=2 \cdot 5$, $7 \cdot 5,12 \cdot 5 \ldots$, and the age groups $15-, 25-, 35-$, $40-, 45 \ldots-75,-80,-85+$, using the Life Table 1 values for 1931, form a nest of cumulative normal curves (Fig. 6), which may be transformed by the use of the normal deviate to a series of straight lines, equidistant at $X=0$ and almost parallel (Fig. 7), which are described by the equation:

$$
\begin{gathered}
Y(b . Z . X)=-0.80+0.08119 X+(0.0800+ \\
0.0004 X) Z \quad \ldots \ldots \ldots \ldots \ldots \ldots \ldots \ldots \ldots
\end{gathered}
$$

where $Y(b . Z . X)=$ Probit of $[i(Z \cdot b . X)$ expressed as a percentage of $I(Z . b)]$.

The standard error of estimate of $Y(b . Z . X)= \pm 0 \cdot 107$.

Fig. 6.-Observed values of $i(Z . b . q)$ fitted with calculated integrated normal curves for $Z=20,30,40,50$, and values of $X$ from 2 to 65 .
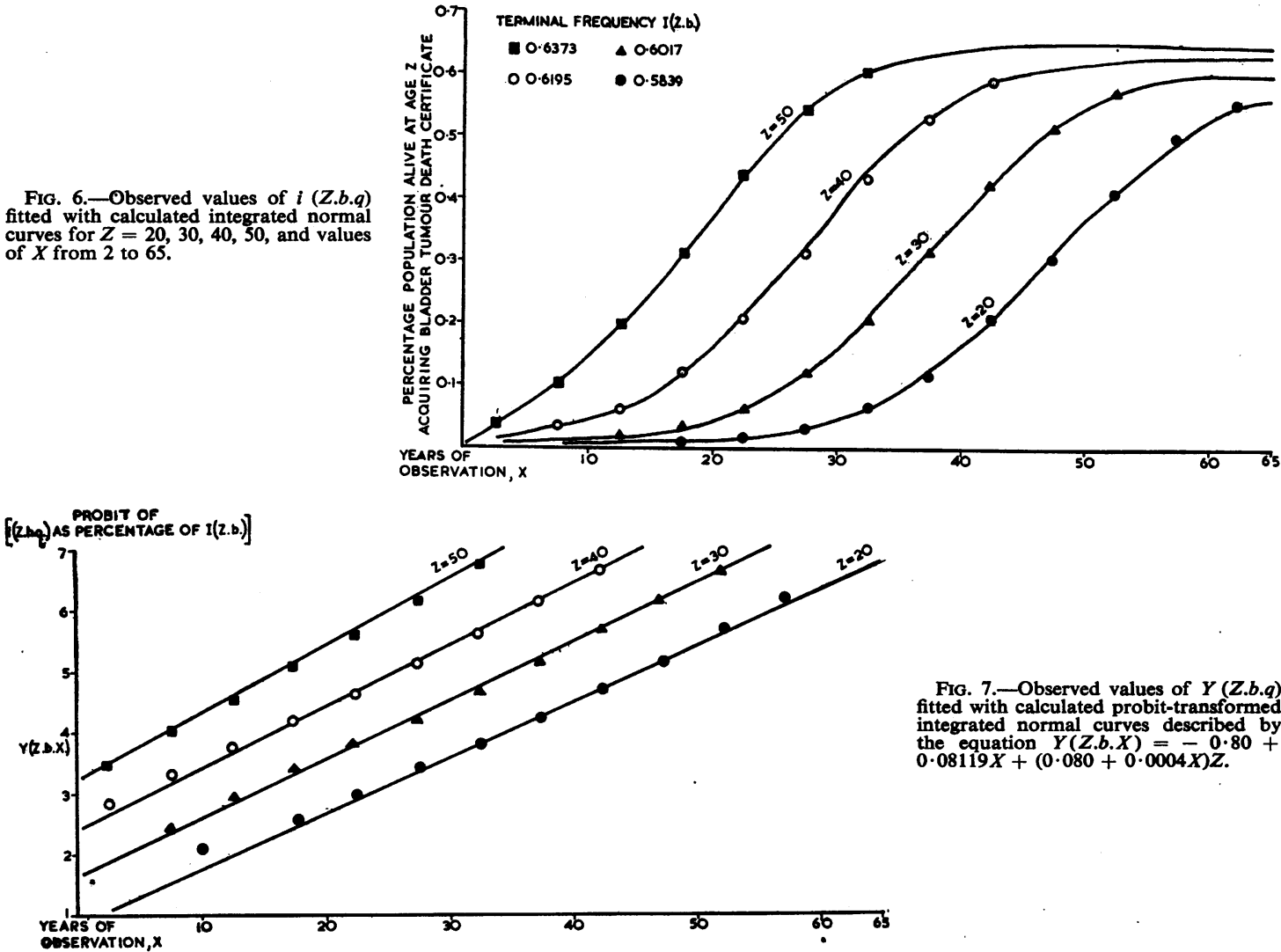

Fig. 7.-Observed values of $\boldsymbol{Y}(\boldsymbol{Z} . b . q)$ fitted with calculated probit-transformed integrated normal curves described by $0.08119 X+(0.080+0.0004 X) Z$. 
The probit (the deviate +5 ) is used because it is a well tabulated function, and the Tables are found in standard works on medical statistics (e.g. Fisher and Yates, 1948).

The values of $I(Z . b)$ for $Z=20,30,40$, and 50 form a linear series which may be described by the equation:

$$
I(Z . b)=0.5483+0.00178 Z
$$

The standard error of estimate $=0.0028$.

Furthermore it is observed that the values of $I(Z . w)$ for $Z=30, w=1921,1931$, and 1948 , and where $M(a . w)$ is based on figures for the triennia 1921-23, 1930-32, and 1947-49 respectively, form a linear regression which may be described as:

$$
I(30 . w)=I(30.1921)+0.0019(w-1921) \ldots(v)
$$

and it is assumed that this expression is valid for values of $Z$ between 20 and 50. From this it may be calculated that $I(Z . b)=I(Z .1935)$. Thus, an estimate $[\bar{I}(Z . w)]$ of $I(Z . b)$, adjusted for the effects of contemporaneous conditions, may be obtained from the expression:

$$
\bar{I}(Z . w)=I(Z . b)+0.0119(w-1935)
$$

which becomes:

$$
\bar{I}(Z . w)=0 \cdot 5483+0 \cdot 00178 Z+0 \cdot 0119(w-1935) .
$$

The whole expression may now be written:

$R(Z . w . X)=$ [Anti-probit $Y(b . Z . X) 0 \cdot 5483+0.00178 Z+$ $0 \cdot 0119(w-1935)] \div 100$

where $Y(b . Z . X)=$ Probit of $[i(Z . b . X)$ as a percentage of $\bar{I}(Z \cdot w)]$.

The standard error of estimate is $\pm \mathbf{0 . 0 1 6 9}$ as determined from the residuals from the $i(Z)$ values for the three triennia 1921-23, 1930-32, and 1947-49 at the values of $X$ and $Z$ already used for the basic data. This gives a total of 111 observations, and the standard error of estimate, adjusted for this number of observations, becomes \pm 0.0171 .

Use of the Equations.-The final estimate $(T)$ of the expected number of death certificates for a class of men defined by environment, but entering the environment at different ages and different times, is given by:

$$
T=\sum \frac{R(Z . w . X) \times P\left(Z . w-\frac{X}{2}\right)}{100} \pm
$$

for all the observed paired values of $Z$ and $w$, where $P=$ the number of persons entering observation at age $Z, w=$ the date of the mid-point of the period for which they are observed, and $X=$ the period of observation.

Equation (vii) may be re-written:

$$
R(Z . w . X)=\frac{\bar{I}(Z . w) \times \text { Anti-probit } Y(b . Z . X)}{100},
$$

and tables of $\bar{I}(Z . w)$ and Antiprobit $Y(b . Z . X)$ can be constructed.
For most practical purposes, $T$ may be used as the final estimate without its standard error of estimate, which is fairly small.

\section{SUMMARY}

The effects of age and contemporaneous conditions upon the frequency of death certificates mentioning tumour of the bladder are discussed for data relating to males in England and Wales between the years 1921 and 1950.

It is shown that the age-specific annual certification rate increases greatly with advancing age until 80 years, after which it drops.

It is also shown that not only is the crude annual certification rate for all ages increasing, but that the corrected annual certification rate, after adjusting for changes in age composition of the population, shows a marked increase. These rates were calculated as mean values of quinquennia.

These observations are used to calculate a series of equations which will give a close estimate of the expected rate of death certification of bladder tumour in a male population subjected to the mean "risk" pertaining in England and Wales. These equations will allow for the age composition of the population observed and for the time at which it was observed.

The equations should be useful in allowing industrial concerns to form a reasonably reliable estimate of the expected rate of the mention of bladder tumour on death .certificates of their members or ex-members, and hence to form a basis for comparison with the number they actually find. This should help in assessing environmental risk.

This work was carried out as part of the programme of a research scheme under the auspicies of the Association of British Chemical Manufacturers.

Miss Drever B. McDonald sorted many years of death certificates into their age groups, and Miss Margery E. Hosker and Miss Joan T. Pearson compiled the alphabetical index of death certificates, and it is a pleasure to acknowledge this assistance.

Thanks are also due to Dr. E. R. A. Merewether, Chief Medical Officer, Ministry of Labour and National Service, for placing most of the death certificates at our disposal, and to the General Register Office for the remaining certificates and for much other help.

\section{REFERENCES}

Case, R.A.M. (1953). Brit. J. industr. Med., 10. In the Press.

Fisher, R.A., and Yates, F. (1948). "Statistical Tables for Biological, Agricultural, and Medical Research". 3rd. ed., p. 50. Oliver and Boyd, London.

Registrar General (1921-1950). " "Statistical Review of England and Wales." Population estimates.

(1949). "Statistical Review of England and Wales, 1940-45." Text, 1, 1.

(1949) Ibid. $1,6$.

- (1948) "Annual Abstract of Statistics (1935-46)", No. 84, p. 27. H.M.S.O., London.

(1951). "Annual Abstract of Statistics (1938-49)", No. 87, p. 33. H.M.S.O., London. 
APPENDIX

DETAILS OF SAMPLE SELECTED FROM 16,163 SINGLE BIRTHS OF KNOWN BIRTH WEIGHT AND DURATION OF GESTATION DELIVERED IN BIRMINGHAM DURING 1947

\begin{tabular}{|c|c|c|c|c|c|c|c|c|c|c|c|c|c|c|c|c|}
\hline \multirow{3}{*}{$\begin{array}{c}\text { Birth } \\
\text { Weight } \\
\text { (lb.) }\end{array}$} & \multicolumn{16}{|c|}{ Duration of Gestation (wks) } \\
\hline & \multicolumn{3}{|c|}{$<35$} & \multirow[b]{2}{*}{$\begin{array}{l}\text { Num- } \\
\text { ber } \\
\text { traced }\end{array}$} & \multicolumn{3}{|c|}{$35-38$} & \multirow[b]{2}{*}{$\begin{array}{l}\text { Num- } \\
\text { ber } \\
\text { traced }\end{array}$} & \multicolumn{3}{|c|}{$39-42$} & \multirow[b]{2}{*}{$\begin{array}{c}\text { Num- } \\
\text { ber } \\
\text { traced }\end{array}$} & \multirow[b]{2}{*}{$\begin{array}{c}\text { Num- } \\
\text { ber } \\
\text { of } \\
\text { births }\end{array}$} & \multicolumn{2}{|c|}{43 and Over } & \multirow[b]{2}{*}{$\begin{array}{l}\text { Num- } \\
\text { ber } \\
\text { traced }\end{array}$} \\
\hline & $\begin{array}{c}\text { Num- } \\
\text { ber } \\
\text { of } \\
\text { births }\end{array}$ & $\begin{array}{c}\text { Sam- } \\
\text { pling } \\
\text { frac- } \\
\text { tion }\end{array}$ & $\begin{array}{l}\text { Percen- } \\
\text { tage } \\
\text { of } \\
\text { sample } \\
\text { traced }\end{array}$ & & $\begin{array}{c}\text { Num- } \\
\text { ber } \\
\text { of } \\
\text { births }\end{array}$ & $\begin{array}{l}\text { Sam- } \\
\text { pling } \\
\text { frac- } \\
\text { tion }\end{array}$ & $\begin{array}{l}\text { Percen- } \\
\text { tage } \\
\text { of } \\
\text { sample } \\
\text { traced }\end{array}$ & & $\begin{array}{c}\text { Num- } \\
\text { ber } \\
\text { of } \\
\text { births }\end{array}$ & $\begin{array}{l}\text { Sam- } \\
\text { pling } \\
\text { frac- } \\
\text { tion }\end{array}$ & $\begin{array}{l}\text { Percen- } \\
\text { tage } \\
\text { of } \\
\text { sample } \\
\text { traced }\end{array}$ & & & $\begin{array}{l}\text { Sam- } \\
\text { pling } \\
\text { frac- } \\
\text { tion }\end{array}$ & \begin{tabular}{|} 
Percen- \\
tage \\
of \\
sample \\
traced
\end{tabular} & \\
\hline$<4 \frac{1}{2}$ & 59 & 1 & 68 & 40 & 52 & 1 & 81 & 42 & 21 & 1 & 71 & 15 & - & - & 一 & - \\
\hline $4 \frac{1}{2}-$ & 73 & 1 & 77 & 56 & 214 & 0.5 & 75 & 80 & 181 & 0.5 & 70 & 64 & 10 & 1 & 60 & 6 \\
\hline $5 \frac{1}{2}-$ & 68 & 1 & 75 & 51 & 670 & $0 \cdot 2$ & 74 & 92 & 1,380 & $0 \cdot 1$ & 81 & 102 & 98 & 1 & 62 & 61 \\
\hline $6 \frac{1}{2}-$ & 87 & 1 & 68 & 59 & 990 & $0 \cdot 1$ & 75 & 63 & 4,145 & 0.02 & 91 & 85 & 292 & 0.5 & 72 & 105 \\
\hline $7 \frac{1}{2}-$ & 48 & 1 & 71 & 34 & 574 & 0.2 & 73 & 90 & 4,236 & 0.02 & 95 & 75 & 316 & $0 \cdot 5$ & 78 & 119 \\
\hline $8 \frac{1}{2}-$ & 12 & 1 & 92 & 11 & 158 & 0.5 & 78 & 52 & 1,666 & $0 \cdot 1$ & 85 & 161 & 148 & 0.5 & 78 & 65 \\
\hline $9 \frac{1}{2}-$ & 5 & 1 & 80 & 4 & 51 & 1 & 63 & 34 & 465 & $0 \cdot 2$ & 80 & 88 & 46 & 1 & 76 & 35 \\
\hline $10 \frac{1}{2}-$ & - & - & - & - & 7 & 1 & 86 & 6 & 73 & 1 & 99 & 72 & 18 & 1 & 83 & 15 \\
\hline
\end{tabular}

CORRIGENDUM

It is regretted that a misprint occurred in Equation (vii) on p. 19 of the January issue of the Journal in the article on "Mortality from Tumours of the Urinary Bladder", by R. A. M. Case. Equation (vii) should read:

$R(Z . w . X)=[$ Anti-probit $Y(b . Z . X)][0.5483+0.00178 Z+0.0119(w-1935)] \div 100$ 